\title{
Potentials of Maize Stalk Ash as Reinforcement in Polyster Composites
}

\author{
Hassan S.B., Oghenevweta E.J.*, Aigbodion V.S. \\ Department of Metallurgical and Materials Engineering, Ahmadu Bello University, \\ Zaria, Nigeria \\ *Corresponding Author: jojolinto@yahoo.com
}

\begin{abstract}
This paper examine the microstructure and the mechanical properties of maize stalk ash particles reinforced polyester composites with the aim of producing a composite material showing enhanced properties for engineering applications. Maize stalk ash particles (MSAp) were added in different volume fractions into a polyester matrix at 5, 10, 15 and 20\% respectively. Composites samples were produced from these mixtures and the effect of the maize stalk ash content on the mechanical and microstructural properties of the composites was investigated and analyzed. Results from the scanning electron microscope (SEM) of the composites show a good and gradual interfacial bonding as the MSAp content increases while the Energy Dispersive spectrometer (EDS) and X-ray diffraction (XRD) show that carbon is present in the ash. The tensile strength, tensile modulus and compressive strength value increases as the maize stalk ash content increases but there is a gradual decrease for the impact strength. These results showed that the maize stalk ash can be used to improve the strength of polymer matrix composites for use in automobile and building applications.
\end{abstract}

Keywords: Maize Stalk Ash, Polyester Resin, Mechanical Properties and Microstructures. 


\section{INTRODUCTION}

To cope with the obvious limitations of polymers, for example, low stiffness and low strength, and to expand their applications in different engineering areas, different types of particulate fillers are often added to process polymer composites, which normally combine the advantages of their constituent phases [1]. Reinforcement of polymers by particulates plays an important role in the improvement of the mechanical properties of high performance materials. Mechanical properties of a polymer can be controlled by the incorporation of well-defined modifier particles in the polymer matrix [2].

The use of agro-sources and wastes as reinforcement in polymer has a reinforcement, have recently attracted the attention of researchers because of their advantages over other established materials. They are environmentally friendly, fully biodegradable, abundantly available, renewable and cheap and have low density [3]. Maize (Zea mays) is of great economic importance. In developing countries such as Nigeria, the harvest of maize is very great [10]. This increasing level of production is due to an increase of the cultivated areas which determines the total amounts of waste generated by the crop after the grain have been harvested. Though, the waste is widely used for feeding livestock fodder, biological conversion to fuels but it is universally appears as waste material after industrial processing and other processes. Frequently, the waste is usually burned as a means of waste disposal. In the light of petroleum shortages and pressure for decreasing the dependence on petroleum products, there is an increasing need in maximizing this waste material.

The successful use of maize fibers in polyethylene matrix composite has been examined but the primary drawback is the lower processing temperature due to the possibility of lignocellulosic degradation and/or the possibility of volatile emissions that could affect composite properties [4]. A study carried out on the use of maize fibers indicate that these fibers have the potential of being used as reinforcing fillers in thermoplastics but they has a great disadvantage of moisture absorption and poor adhesion [5].

The mechanical properties of particle-polymer composite has been over the decades has attracted 
many researchers because of the improved properties it offers. The tensile strengths of nylon 6,6/kaolin/glass particles has been carried out[6]. It was shown that the composite strength is increased when the interface adhesion is improved. The tensile modulus of hydroxyapatite (HA) filled polymer composites has been studied [7]. It was found that the tensile modulus is increased by $50-100 \%$ by adding $10 \%$ vol of kenaf particles. Similar results for other particulate-polymer composite systems have also been obtained. For example, it is observed that the tensile modulus of ternary polymer composites: polyamide 6,6 (PA6,6)/poly[styrene-b-(ethylene-co-butylene)-bstyrene] is enhanced by adding glass beads. Also, the modulus of epoxy/glass bead composites increases with glass beads [8]. Similarly, the tensile modulus of nylon 6/silica particles composites increases constantly with increasing silica loading [9]. Hence, addition of particles to a polymer matrix can easily improve the tensile modulus of the polymer since the rigidity of the inorganic fillers is generally much higher than that of the organic polymers.

The aim of this study is to investigate the microstructure and mechanical properties of maize stalk ash particles reinforced polymer (polyester) composites materials in order to develop an engineering material for novel configurations in automotive industries such as car bumper and in the building sectors such as house tiles.

\section{MATERIALS AND METHODS}

The maize stalk that was used was obtained from a harvested agricultural farm in Samaru, ZariaKaduna State, Nigeria. The base polyester resin, accelerator (Cobalt Octoate) and catalyst (Methyl ethyl Ketone Peroxide (MEKP)) was obtained from Steve Moore Chemicals, ZariaKaduna State, Nigeria.

The collected maize stalk tegument was dried in the sun and ground to a fine powder using electrical milling machine. The fine powder was carbonized at a temperature of $1200^{\circ} \mathrm{C}$ in an electric resistance furnace which take place in the absence of oxygen in order to form the maize stalk ash. 
The maize stalk ash was then sieved unto a set of sieves arranged in descending order of fineness and particle size analysis was carried out in accordance with BS 1377:1990 [8]. A particle size of $53 \mu \mathrm{m}$ was selected and used [16].

In synthesizing the reinforced polyester composites, the unsaturated polyester was measured into a beaker and the maize stalk ash was added and then stirs until even dispersion was achieved. Addition of $1 \%$ weight of catalyst was made and stirred for 3mins, after which $2 \%$ weight of accelerator was added and stirred for another 3mins before casting the sample into a mould. The mould was cleaned with acetone and coated with polyvinyl alcohol (PVA) and allowed to dry before the sample were cast. This procedure was repeated for all samples produced with changes in the percentage of the maize stalk ash particles.

The microstructures of the maize stalk ash particles, polyester resin matrix and the composites developed were carried out using SEM and EDAX equipment, model Leica Cambridge S-360. The impact strengths of the composite developed (120x10x4mm sample) were determined using Charpy impact tester (Changteh China, Model JC-25 4J). The tensile strengths and tensile modulus of the polyester/maize stalk ash particulate developed specimen with dimension 60x6x3mm were determined using the Instron machine (model 5564) with cross-head speed of $5 \mathrm{~mm} / \mathrm{min}$, at room temperature, according to ASTM D 638-90.

\section{RESULTS AND DISCUSSION}

The results of test conducted on the control and the developed composites are presented as follows: Table 1 show the results obtained from the mechanical tests. The SEM microstructure/EDS of the MSAp and its XRD result are shown in Figure 1 and Figure 2 respectively while the chemical compositions as obtained from XRD are shown in Tables 2. The SEM microstructure/EDS of the unreinforced polyester matrix are shown in Figure 3 while those of the developed composites are shown in Figure 4-7. Figures 8-12 show the variation of the mechanical properties with weight percent of MSAp additions. 
Table 1: Mechanical Properties of Maize Stalk Ash Particles Reinforced Polyester

\begin{tabular}{|c|c|c|c|c|c|}
\hline $\begin{array}{c}\text { \% wt Maize } \\
\text { Stalk Ash } \\
\text { particulates }\end{array}$ & $\begin{array}{c}\text { Tensile } \\
\text { Modulus } \\
(\mathrm{MPa})\end{array}$ & $\begin{array}{c}\text { Tensile } \\
\text { Strength } \\
(\mathrm{MPa})\end{array}$ & $\begin{array}{c}\text { Compressive } \\
\text { Strength } \\
(\mathrm{MPa})\end{array}$ & $\begin{array}{c}\text { Impact } \\
\text { Strength } \\
(\mathrm{J})\end{array}$ & $\begin{array}{c}\text { Hardness } \\
\text { Values } \\
(\mathrm{HR})\end{array}$ \\
\hline 0 & 159.55 & 35.10 & 19.12 & 0.90 & 19.70 \\
\hline 5 & 203.65 & 39.52 & 20.20 & 0.88 & 26.10 \\
\hline 10 & 421.74 & 48.50 & 25.50 & 0.87 & 36.30 \\
\hline 15 & 794.56 & 50.46 & 29.78 & 0.85 & 48.80 \\
\hline 20 & 824.62 & 53.60 & 30.32 & 0.78 & 57.80 \\
\hline
\end{tabular}
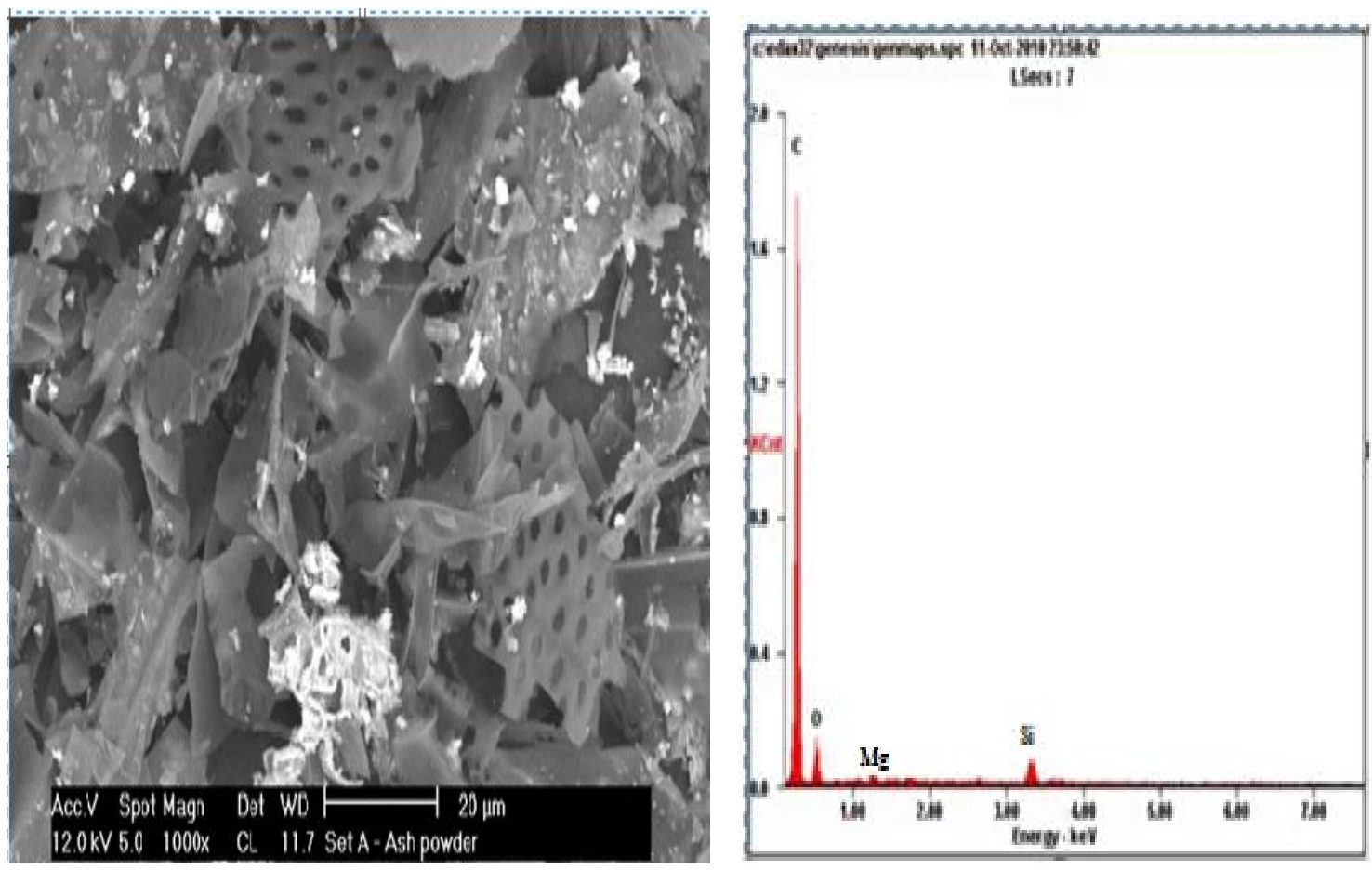

Figure 1: SEM microstructure of maize stalk ash particles (MSAp) (x1000)/EDS 


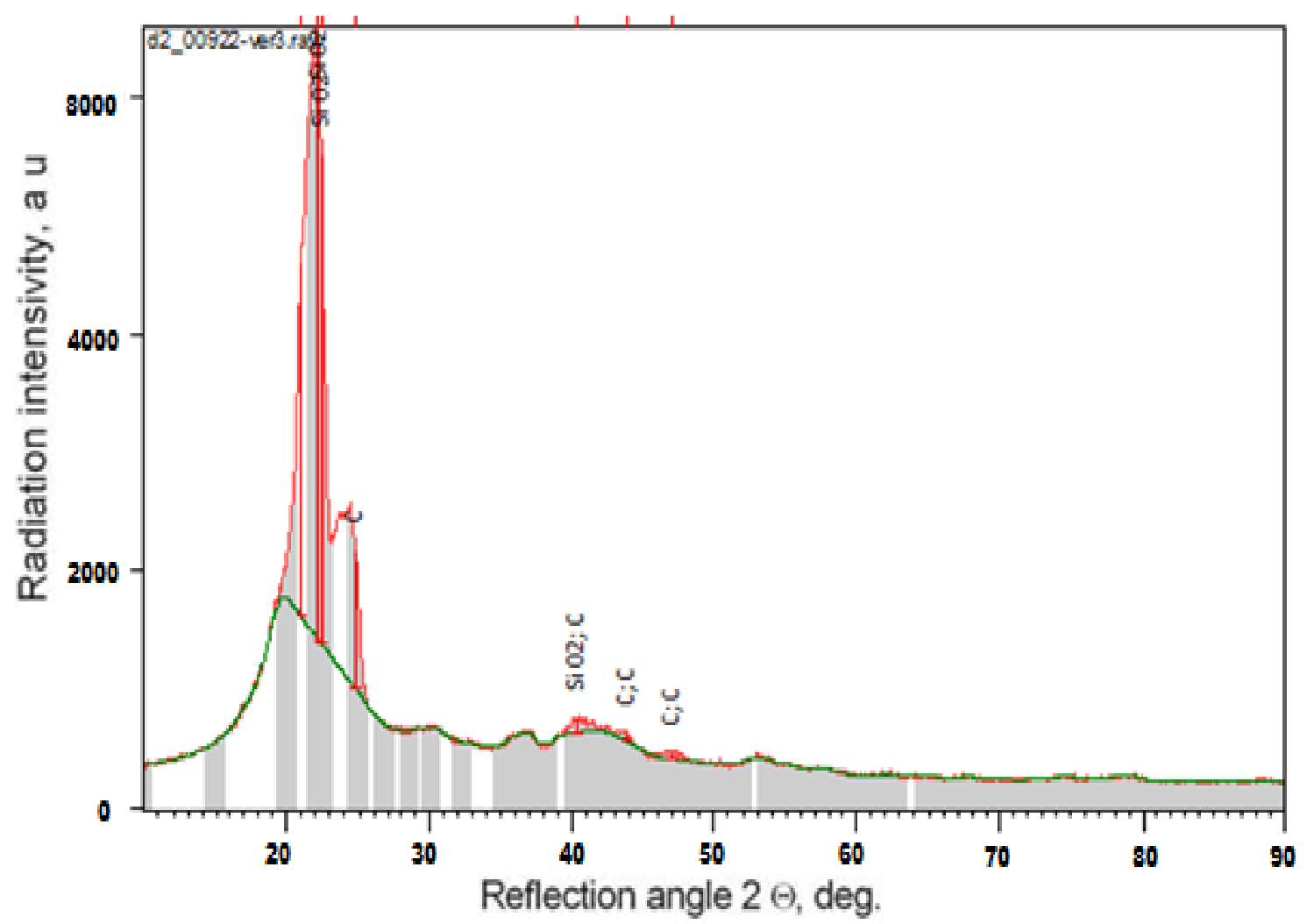

Figure 2: X-ray diffraction (XRD) pattern of the MSAp.

Table 2: Chemical composition of the MSAp as obtained from XRD.

\begin{tabular}{|c|c|c|c|c|c|c|}
\hline Visible & Ref. Code & Score & $\begin{array}{c}\text { Compound } \\
\text { Name }\end{array}$ & $\begin{array}{c}\text { Displaceme } \\
\left.\text { nt [ }{ }^{\circ} 2 \mathrm{Th} .\right]\end{array}$ & $\begin{array}{l}\text { Scale } \\
\text { Factor }\end{array}$ & $\begin{array}{l}\text { Chemical } \\
\text { Formula }\end{array}$ \\
\hline * & $\begin{array}{r}00-026- \\
1081\end{array}$ & 31 & Carbon & 0.000 & 0.017 & C \\
\hline * & $\begin{array}{r}01-082- \\
1555\end{array}$ & 28 & $\begin{array}{l}\text { Silicon } \\
\text { Oxide }\end{array}$ & 0.000 & 0.895 & $\mathrm{SiO}_{2}$ \\
\hline * & $\begin{array}{r}01-074- \\
2329\end{array}$ & 25 & Graphite & 0.000 & 1.228 & C \\
\hline
\end{tabular}



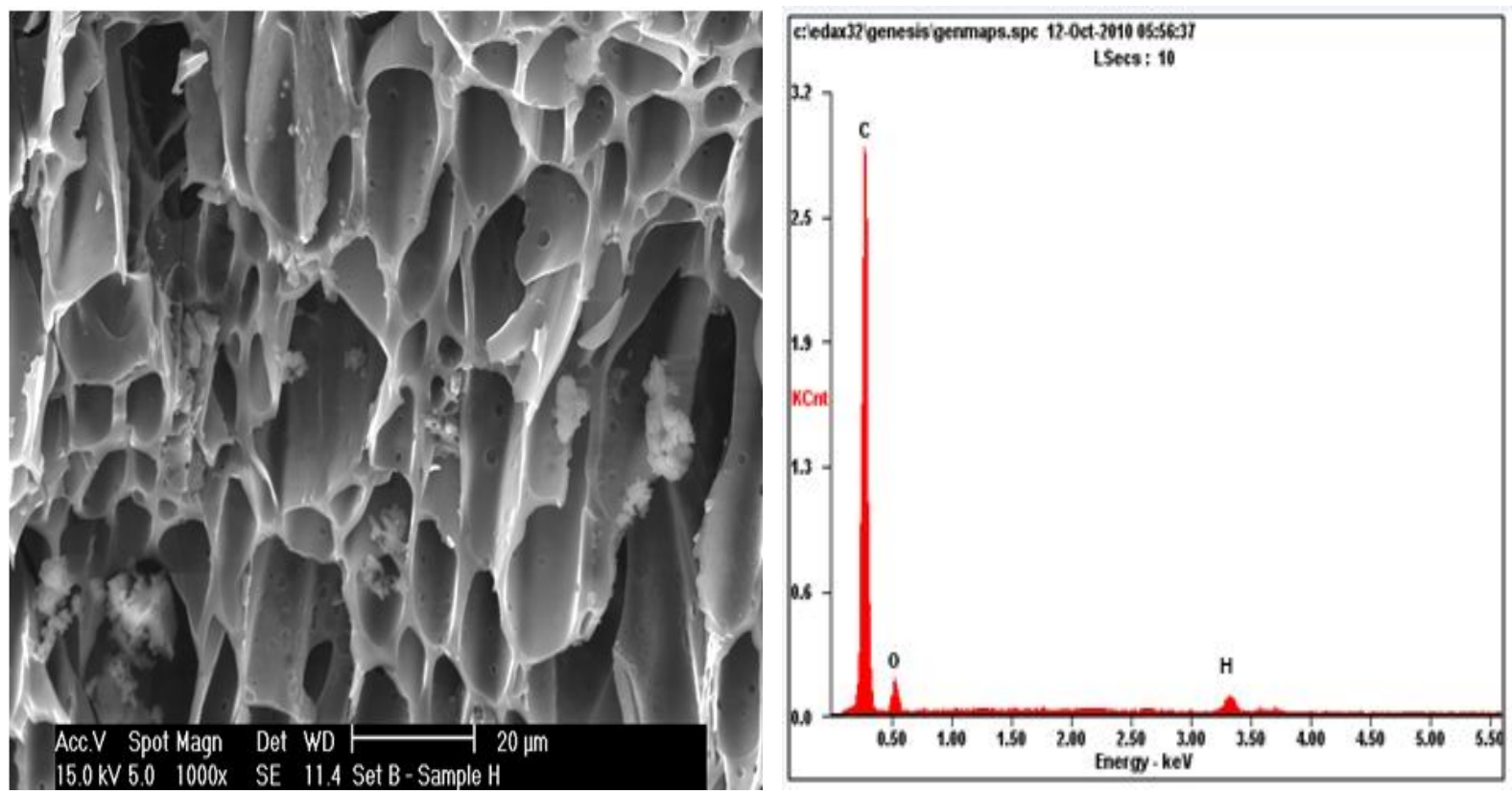

Figure 3: SEM microstructure of the polyester resin (x1000)/EDS
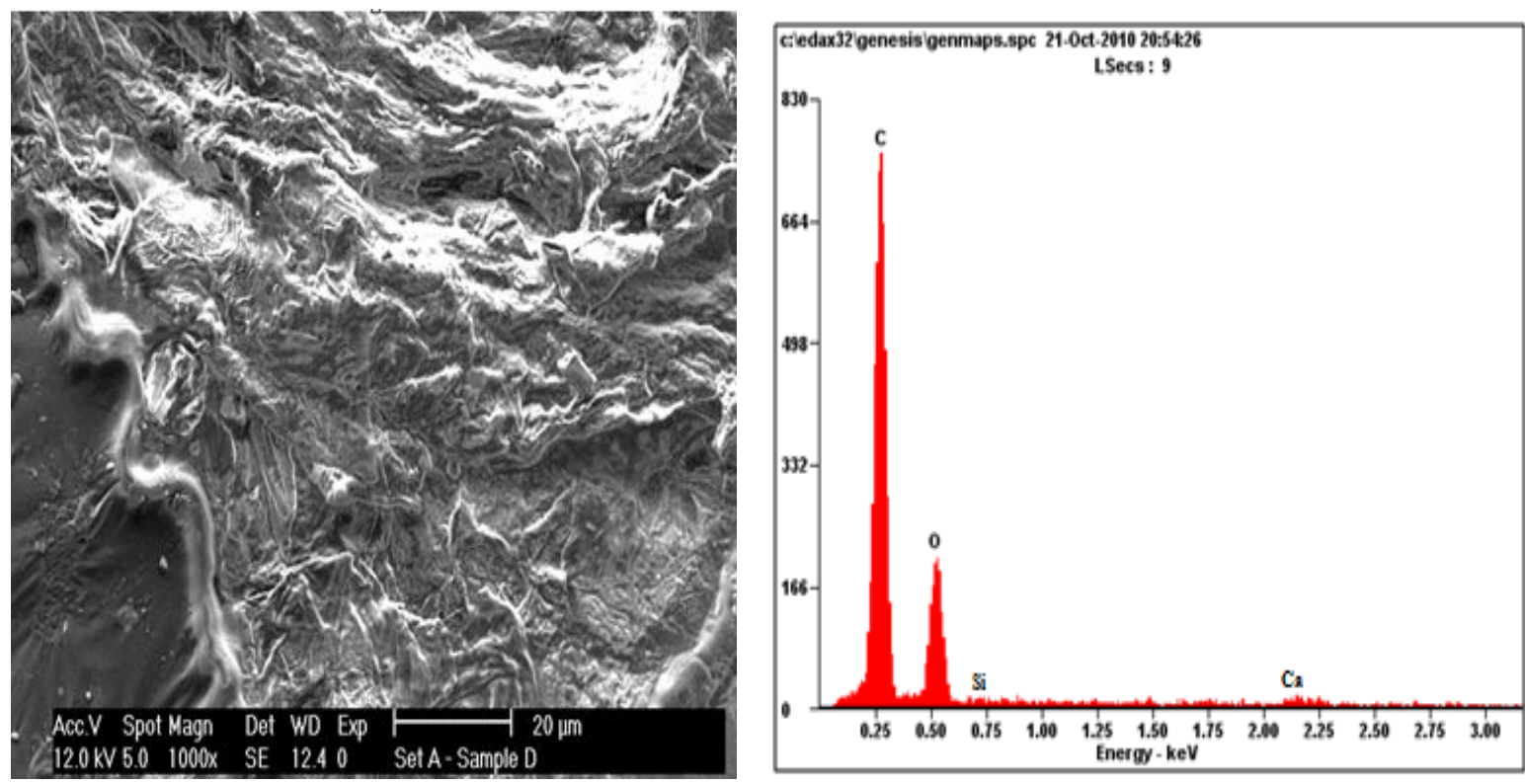

Figure 4: SEM microstructure of the 5wt\% MSAp reinforced polyester resin (x1000)/EDS 

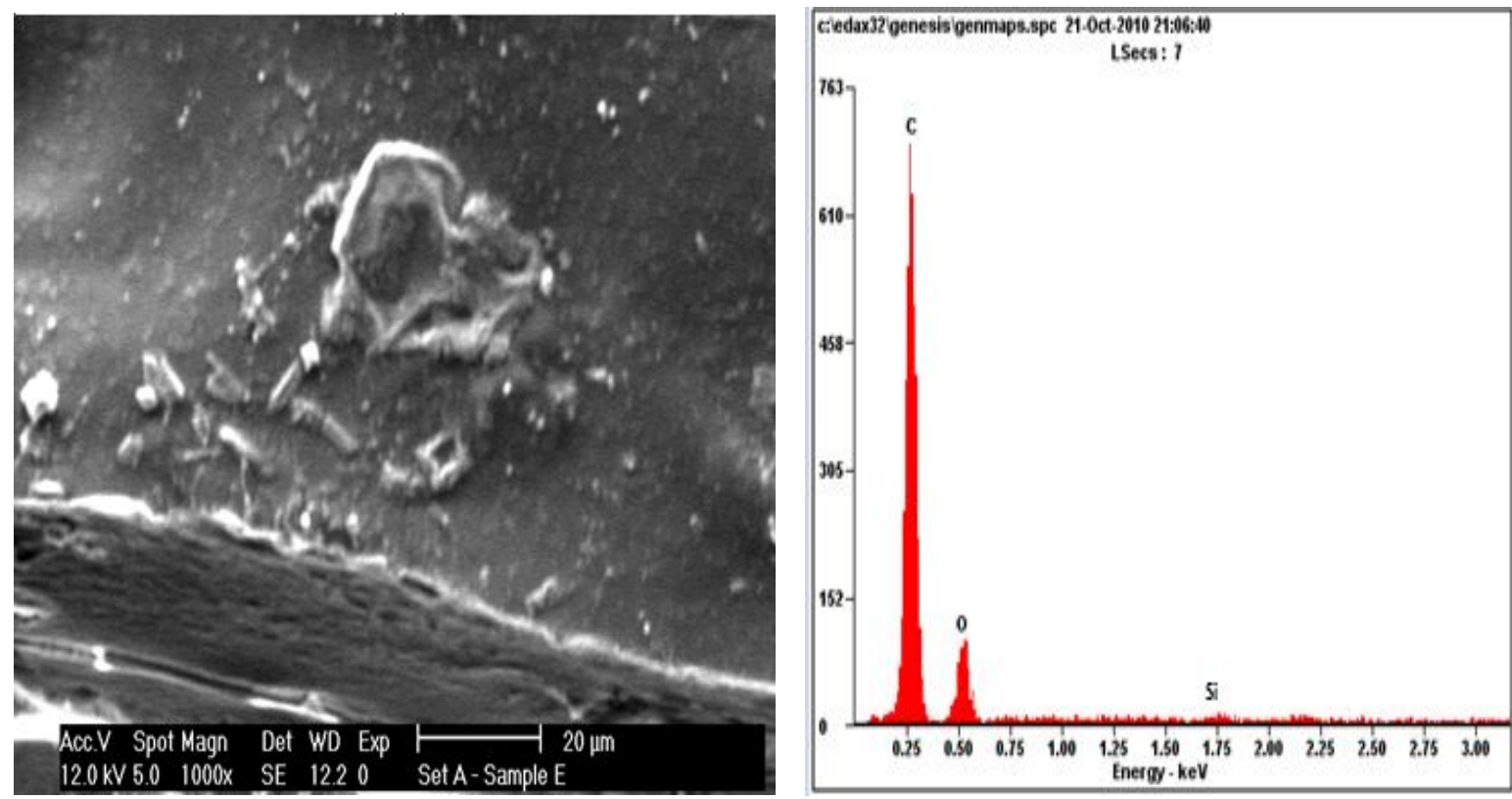

Figure 5: SEM microstructure of the 10wt\% MSAp reinforced polyester resin (x1000)/EDS
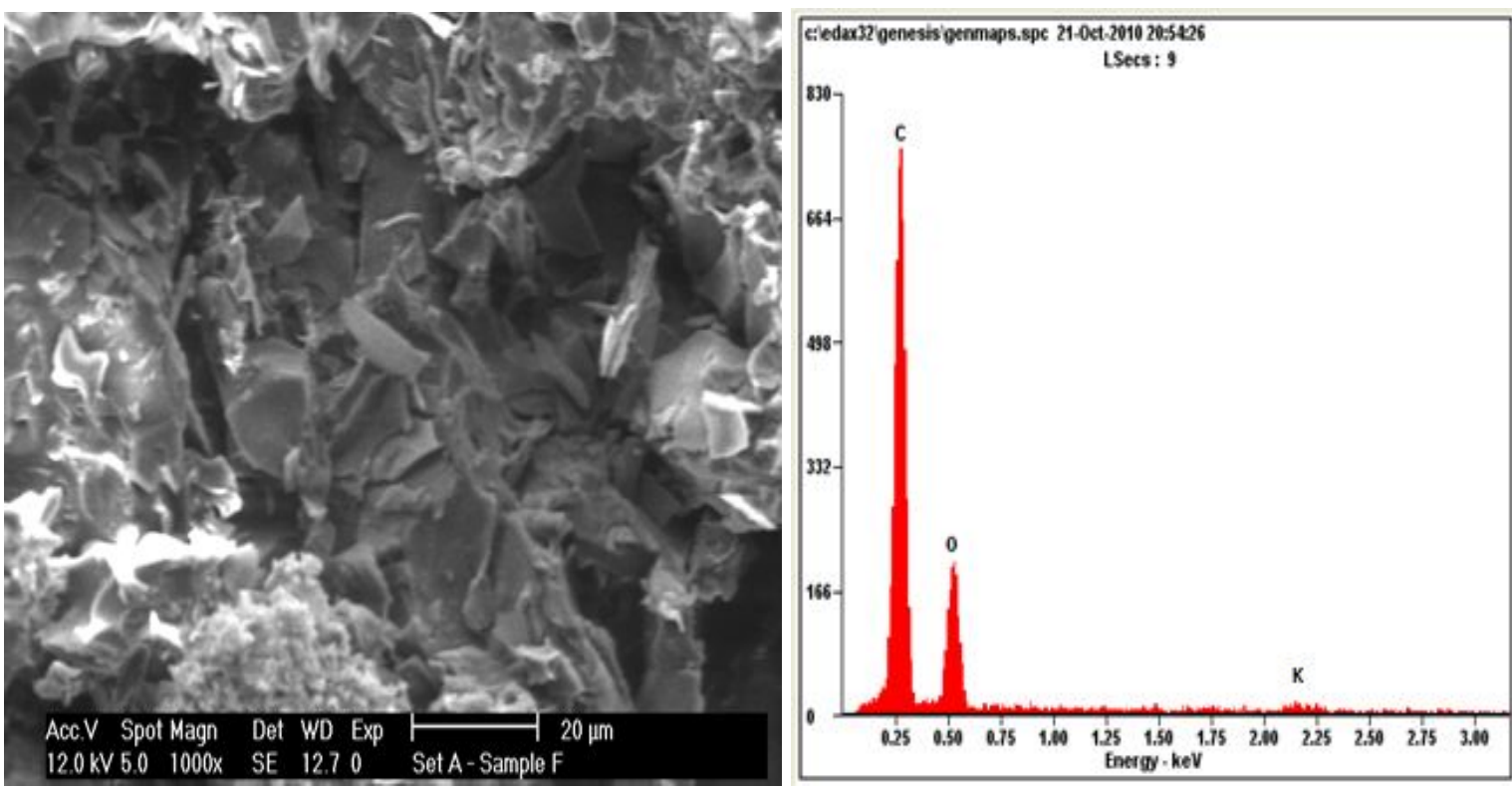

Figure 6: SEM microstructure of the 15wt\% MSAp reinforced polyester resin (x1000)/EDS 

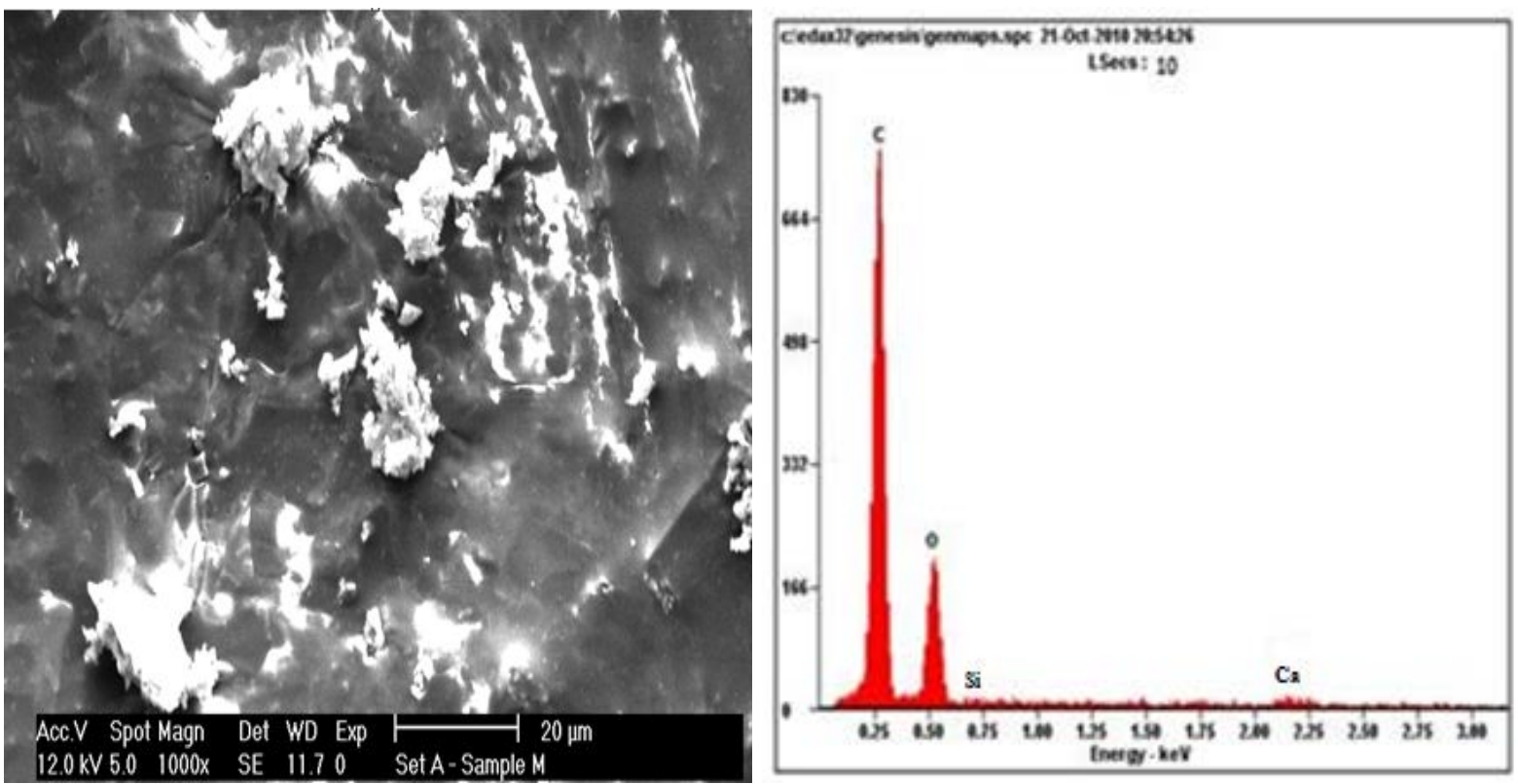

Figure 7: SEM microstructure of the 20wt\% MSAp reinforced polyester resin (x1000)/EDS

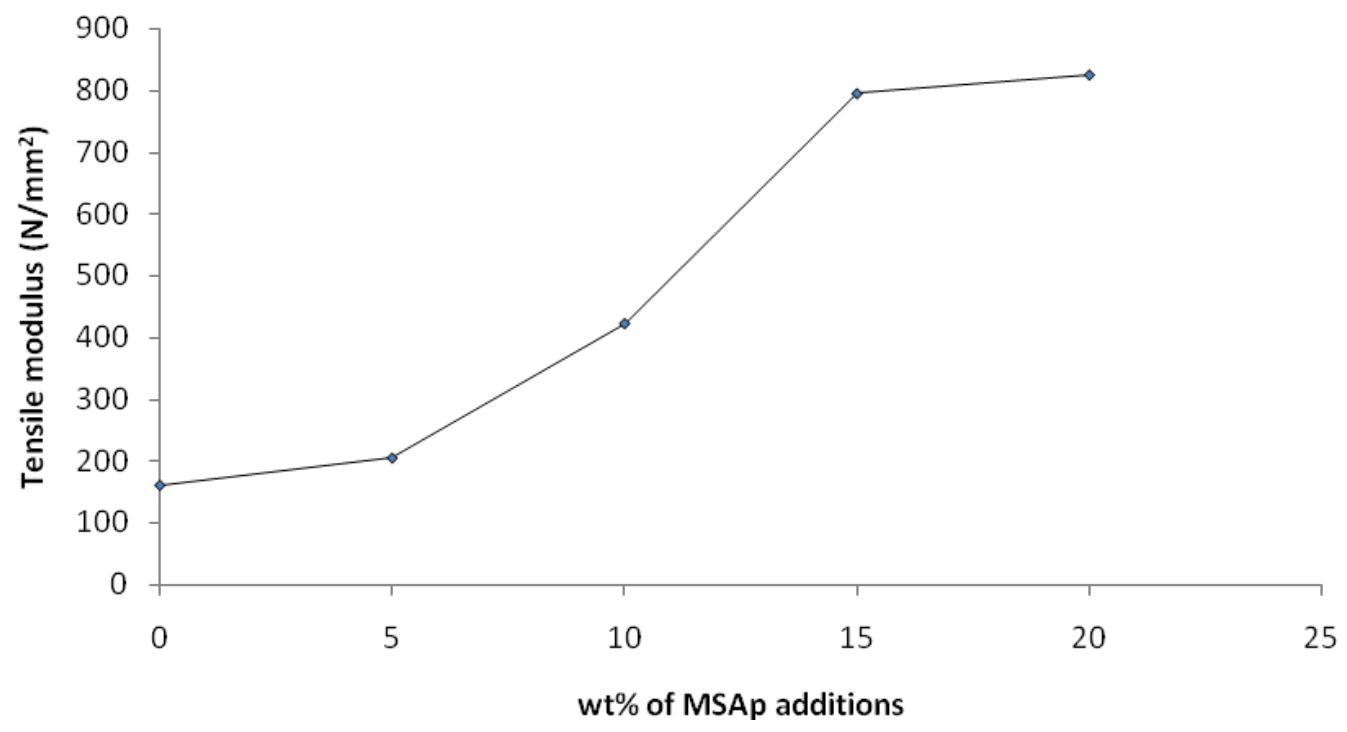

Figure 8: Variation of tensile modulus with weight percent of MSAp additions 


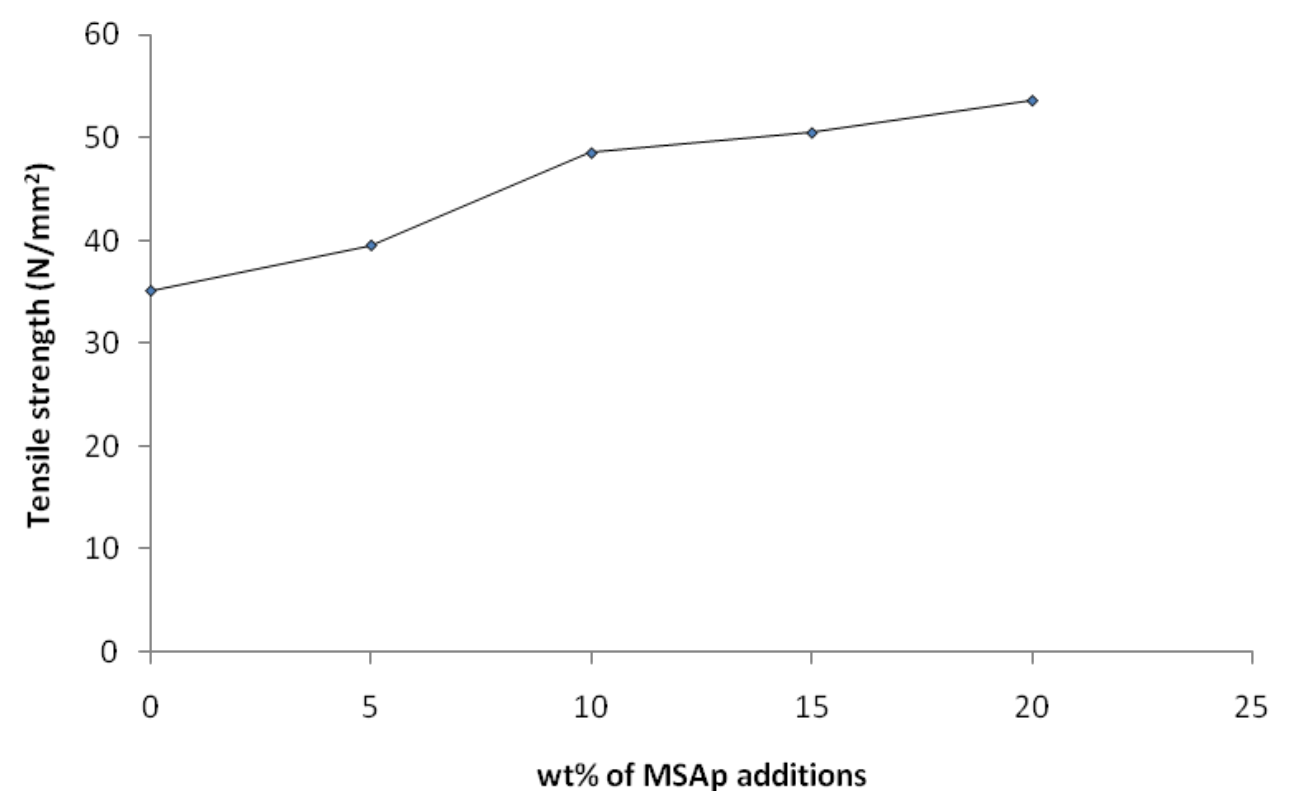

Figure 9: Variation of tensile strength with weight percent of MSAp additions.

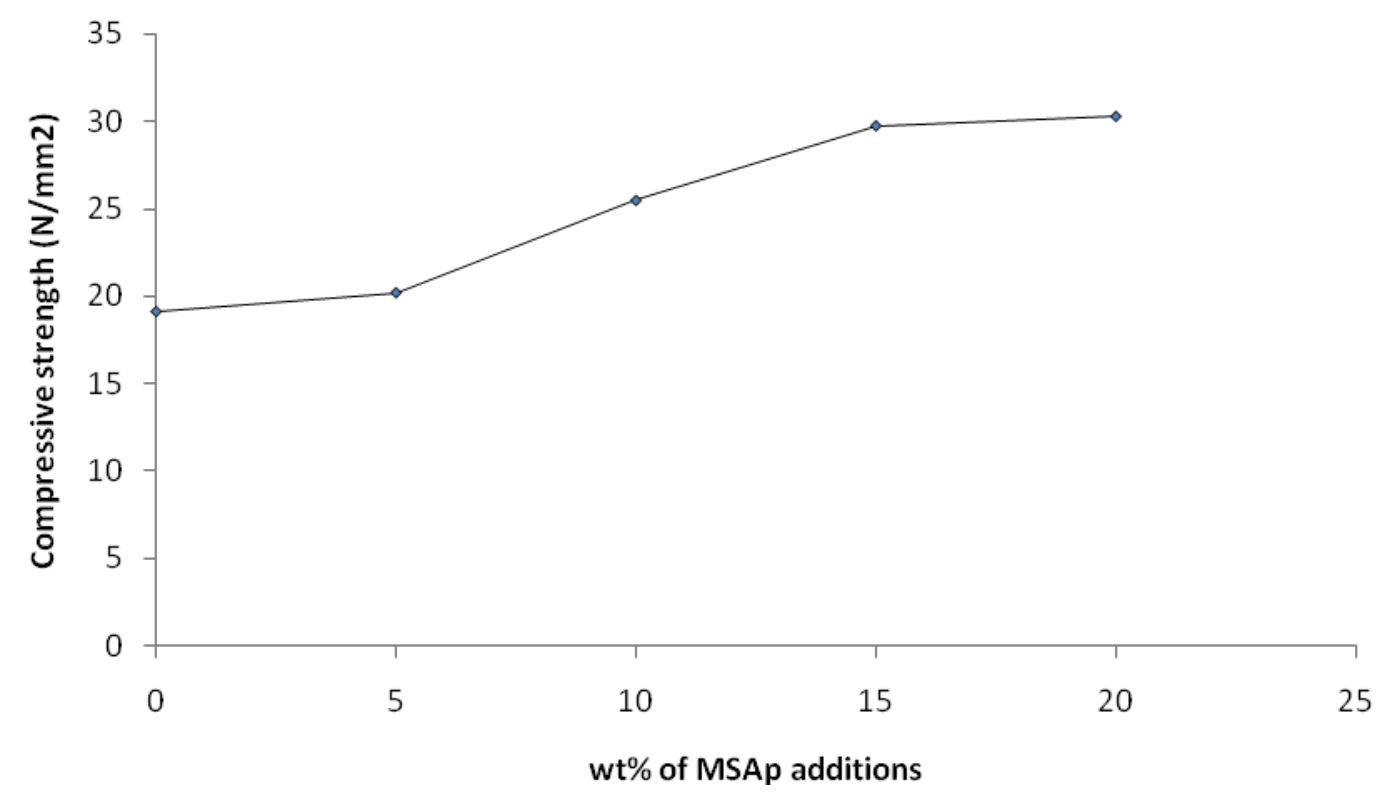

Figure 10: Variation of compressive strength with weight percent of MSAp additions. 


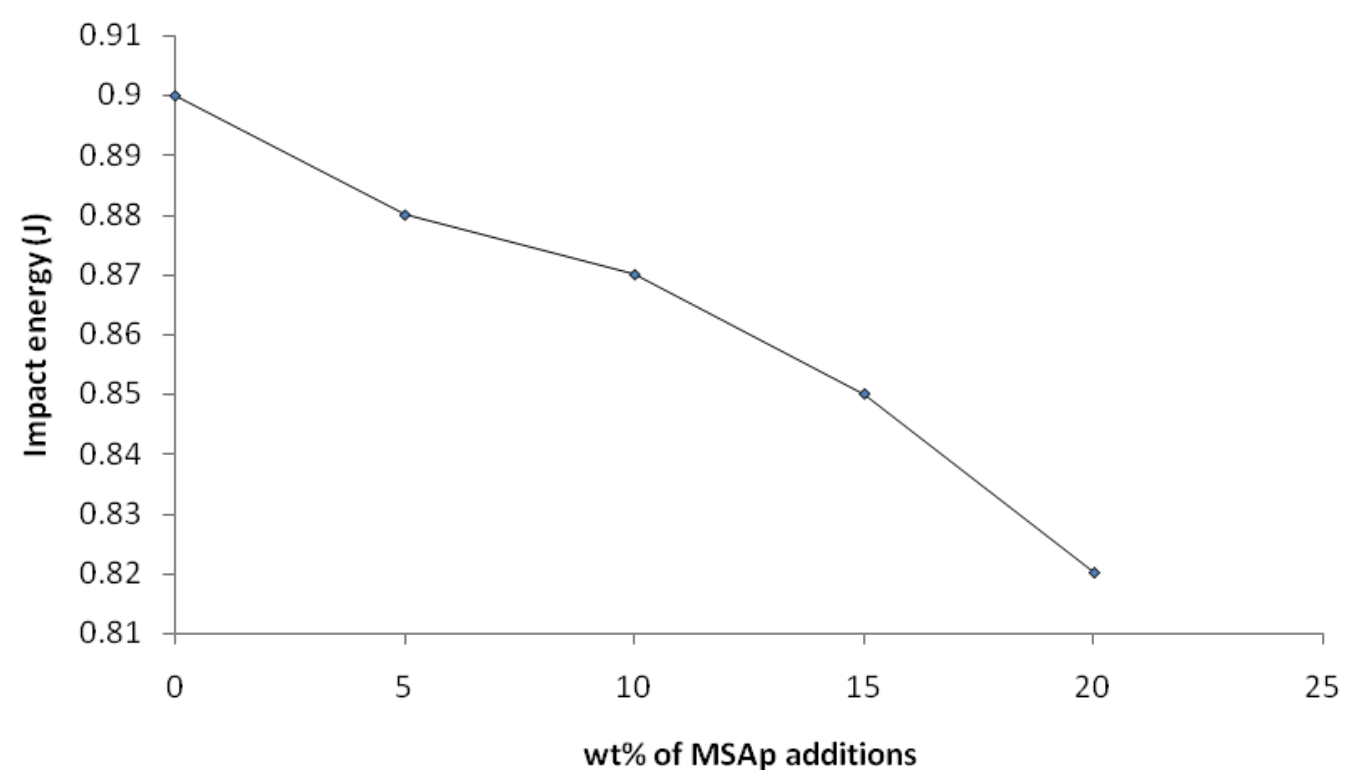

Figure 11: Variation of impact energy with weight percent of MSAp additions.

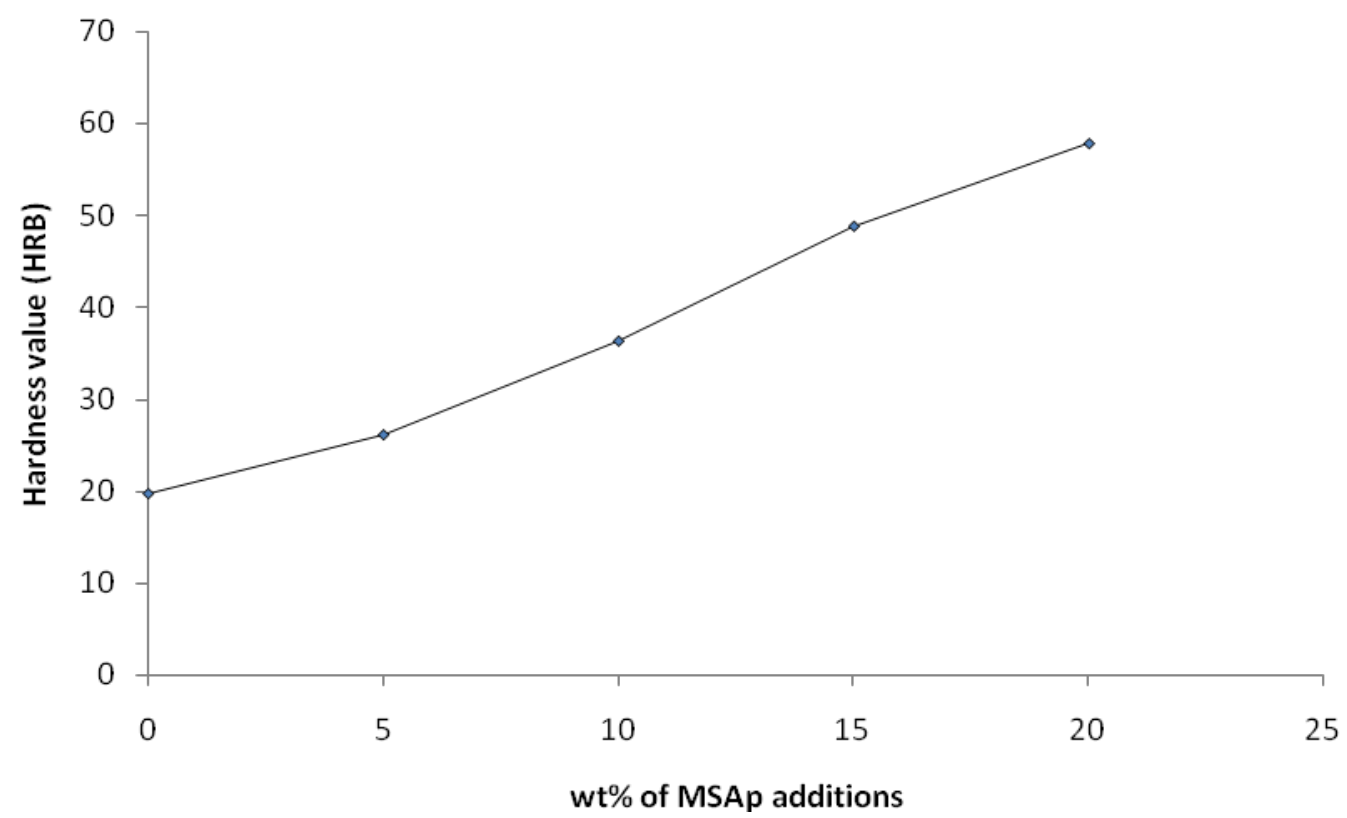

Figure 12: Variation of hardness value with weight percent of MSAp additions. 


\subsection{Microstructural and XRD Analyses}

The microstructural analysis using the scanning electron microscope (SEM) show clearly the difference in the morphology of the unreinforced polymer (see Figure 3) as compared to those reinforced with maize stalk ash particulates (see Figures 4-7). It can be seen clearly that there is microstructural change as the maize stalk ash particles addition to the polyester increases.

From the SEM microstructure of the maize stalk ash particulates (MSAp) (see Figure 1), it clearly reveal that the particle size and shape varies. From the EDS spectrum it can be seen clearly that the elemental composition of the MSAp was reveal. The polyester matrix (Figure 3) as revealed from the SEM spectrum shows the inter-lamina boundaries of the amorphous and spherulites structures. From the EDS spectrum it can be seen clearly that the elemental composition of the polyester resin was reveal. Also, from the EDS spectral it can be seen clearly that the elemental composition of the composites developed were revealed. Figures 4-7 indicate a good and interfacial bonding between the MSAp and the matrix.

The X-ray diffraction pattern obtained for MSAp (see Figure 2) displays numerous diffraction peaks, which reflect the diffraction intensities. As it can be seen in Figure 2, the visible phases at these peaks are carbon (C), silicon oxide $\mathrm{SiO}_{2}$ and graphite (C).

\subsection{Mechanical Properties Analysis}

The mechanical properties of particulate-polymer composites depend strongly on the particlematrix interface adhesion, stress-strain behavior of the filler and/or the matrix, and volume of particle loading.

The tensile modulus and tensile strength increases with increasing weight percent of MSAp additions (see Figures 8 and 9 respectively and Table 1). The increase of tensile modulus from $159.55 \mathrm{~N} / \mathrm{mm}^{2}$ for the polyester matrix to $824.62 \mathrm{~N} / \mathrm{mm}^{2}$ may be attributed to the higher crosslink density of the polyester and good distribution of MSAp in the polyester matrix. This uniformity of MSAp distribution has efficiently hinders the chains movement during deformation leading to high fibril orientation. This mechanism will increase the stiffness of the composites as well as the 
tensile modulus. These results are in agreement with the SEM results obtained and also in agreement with earlier research [10-11]. The increase in tensile strength from $35.0 \mathrm{~N} / \mathrm{mm}^{2}$ to $53.60 \mathrm{~N} / \mathrm{mm}^{2}$ of the developed composites is primarily because the developed composites contained well-bonded MSAp, good MSAp dispersion and strong polyester/MSAp interface adhesion for effective stress transfer. This observation is in agreement with earlier research [12]. The compressive strength of the polyester resin and the reinforced polyester composites are presented in Figure 10 and Table 1. It is clear that the compressive strength of the polyester/MSAp composites increases from $19.12 \mathrm{~N} / \mathrm{mm}^{2}$ to $30.32 \mathrm{~N} / \mathrm{mm}^{2}$. The increase in the compressive strength of the developed composites is due to good interfacial bonding between the matrix and the MSAp and uniform distribution of the MSAp in the matrix. This leads to hardening of the matrix by the MSAp.

From the impact test carried out, the impact energy of the developed composites decreases with the addition of the MSAp (see Table 1 and Figure 11). This is because as the percent weight of MSAp additions increases, the energy absorption mechanism at the surface of the MSAp and the polyester/MSAp interface is not efficient. This means that the MSAp could not pin down the crack formed effectively thereby the velocity of crack propagation through the polyester matrix increases. This observation shows that all the dissipated energies during the impact test are only absorbed by the polyester matrix without positive contribution from the MSAp to enhance the impact energy. This is in agreement with earlier findings [13].

Results of the hardness value as showed in Figure 12 and Table 1 indicate that the hardness values of the developed composites increases as the MSAp are added. The increase in hardness is related with the increasing amount of hard and brittle MSAp in the polyester matrix. This hard MSAp will continuously resist deformation due to indentation.

\section{CONCLUSION}

From the mechanical and microstructural analysis of the polyester/maize stalk ash particulate composite, it has given us information about the suitability of maize stalk ash particles as a source of reinforcement in polymer matrix composite. This means that this research has added 
another agro-waste and biodegradable material to the several types used for reinforcement. Therefore, it can be concluded from the results obtained that the developed composites have shown improved mechanical properties as compared with the unreinforced polyester resin.

\section{REFERENCES}

[1] Bucknall, C.B. Rubber toughening. In: The Physics of Glassy Polymers. Chapman \& Hall, London, 1997; pp. 363-412.

[2] Nakamura Y, Yamaguchi M, Okubo M, Matsumoto T. Effects of particle size on mechanical and impact properties of epoxy resin filled with spherical silica. J. Appl Polym Sci 1992; 45:1281-9.

[3] Mori T, Tanaka K. Average stress in matrix and average energy of materials with misfitting inclusions. Acta Metal 1973; 21: 571-4.

[4] Curtu and D. Motoc Luca. Theoretical and Experimental Approach of multiphase composite materials in DAAAM International Scientific Book, B. Katalinic, Ed. Vienna: DAAAM International Publishing, 2009, pp. 349-362.

[5] Tavman, I. H. Thermal and mechanical properties of aluminium powder-filled high density polyethylene composites. Journal of Applied Polymer Science, Vol. 62, 1996, pp. 21612167.

[6] Lombardo, N. Effect of an inhomogeneous interphase on the thermal expansion coefficient of particulate composite. Composites Science and Technology, Vol. 65, 2005, pp. 21182128.

[7] Wang M., Berry C., Braden M., and Bonfield W., (1998) Young's and shear moduli of ceramic particle filled polyethylene. J Mater Sci Mater Med; 9: 621-4.

[8] Tjong S.C., and Xu S.A. (2001). Ternary polymer composites: PA6,6/maleated SEBS/glass beads. J Appl Polym Sci;81:3231-7.

[9] Amdouni N., Sautereau H., and Gerard J.F. (1992). Epoxy composites based on glass-beats: Mechanical-properties. J Appl Polym Sci;46: 1723-35.

[10] Munoz, A. Potential of Maize-Lime Pozzolana Coomposite to Develop low cost Housing Composite. Proceedings of NOCMAT, 2008. Cali Colombia. 
[11] Amdouni N., Sautereau H., and Gerard J.F. Epoxy composites based on glass-beats: Mechanical-properties. J Appl Polym Sci;46: 1992; 1723-35.

[12] Ismail, H., Rozman, H. D., Jaffri R. M., and Mohd Ishak, Z. A. Oil Palm Wood Flour Reinforced Epoxidized Natural Rubber Composites: The effect of filler content and size,” Euro. Poly. J., 33, 10-12, 1997; pp. 1627-1632.

[13] Ou Y., Yang F., and Yu Z. A new conception on the toughness of nylon 6/silica nanocomposite prepared via in situ polymerization. J Polym Sci Part B Polym Phys;36: 1998; 789-95.

[14] Kendall K. Fracture of particulate filled polymers. Brit Polym J;10: 1987;35-8.

[15] Oghenevweta, E.J. The potential of using maize stalk ash as reinforcement in polymer matrix particulate composite, M.Sc on-going, Department of Metallurgical and Materials Engineering, Ahmadu Bello University, Zaria, Nigeria, 2011.

[16] Yang, H.S., Kim, H.J., B.J. and Hawng, T.S. Rice husk flour filled polypylene composites; mechanical and morphological study. Compost. Struct. 63: 305-312. 